Jpn. J. Med. Mycol.

Vol. 22, 202-214, 1981

ISSN 0593-0516

\title{
Ultrastructure and Chemistry of Cell walls of Geotrichum candidum: With Special Reference to Conidiogenesis
}

\author{
Yoshinori Nozawa**, Reiko Kasai and Garry T. Cole* \\ Department of Biochemistry, Gifu University School of Medicine, Gifu 500, Japan and \\ *Department of Botany, University of Texas at Austin, Texas 78712, U.S.A.
}

[Received for Publication: February 5, 1981]

\begin{abstract}
The conidiogenesis of Geotrichum candidum grown on Czapek agar containing $1 \%$ yeast extract was examined by electron microscopy. The results showed that the entire wall of the fertile hypha is incorporated into the conidial wall and also that increase in thickeness of the inner wall layer and differentiation of crosswalls are likely to be due to new wall synthesis which occur during conidium formation. Furthermore, the chemical composition was analysed for the purified conidial walls, and was compared with that of haloarthric conidial walls produced by Trichophyton mentagrophytes.
\end{abstract}

Geotrichum candidum Link ex Pers. is an imperfect fungus which is commonly isolated from soil ${ }^{1)}$ and frequently incriminated in food contamination and spoilage ${ }^{2}$. In addition, G. candidum has been reported as part of the indigenous microflora of the gastrointestinal tract of animals, including mans). Under conditions which compromise the host's immunological defenses, this apparently innocuous resident of the gut may become pathogenic and cause oral, gastrointestinal or bronchopulmonary infections in $\operatorname{man}^{3,4)}$ and cutaneous or renal infections in other animals ${ }^{5 \sim 77}$. The fungus typically produces conidia by simple fragmentation and disarticulation of fertile hyphae (i.e. holoarthric conidium formation) $)^{8}$. The fertile hyphae are produced from either aerial mycelia on solid substrates, or immersed mycelia in liquid growth media. Rapid growth and sporulation in simple liquid media have permitted extensive developmental and biochemical studies of G. candidum in chemostat culture and allowed investigators to examine endogenous and exogenous factors controlling condiogenesis ${ }^{9 \sim 17}$ ). In this paper, we have reviewed significant developmental and ultrastructural aspects of conidium formation

**To whom inquiries regarding the paper should be addressed. in G. candidum and examined the fine structure and chemical composition of conidial walls. A comparison of chemical data derived from other investigations of hyphal and holoarthric conidial wall composition is also presented. The potential of utilizing $G$. candidum as an experimental model for studies of various morphogenetic aspects of septate fungi is discussed.

\section{MATERIALS AND METHODS}

Culturing Procedures. The strain of Geotrichum candidum used in this study was obtained from J. W. Carmichael, University of Alberta, Canada (UAMH 178) and maintained in the University of Texas fungal culture collection (UT 22). The fungus was grown on Czapek agar (Difco) plus $1 \%$ yeast extract in Petri dishes for 7-10 days at $28^{\circ} \mathrm{C}$ in continuous darkness. Blocks of agar $(5 \mathrm{~mm}$ square) supporting growth of conidia and mycelium were excised from the edge of the sporulating colony and a single agar block was used to inoculate each $400 \mathrm{ml}$ Erlenmeyer flask containing $150 \mathrm{ml}$ of liquid media (composition of media: sucrose, $30 \mathrm{~g}$ : $\mathrm{NaNO}_{3}, 2 \mathrm{~g} ; \mathrm{K}_{2} \mathrm{HPO}_{4}, 1 \mathrm{~g} ; \mathrm{KCl}, 0.5$ $\mathrm{g} ; \mathrm{MgSO}_{4} \cdot 7 \mathrm{H}_{2} \mathrm{O}, 0.5 \mathrm{~g} ; \mathrm{FeSO}_{4}, 0.01 \mathrm{~g}$; yeast extract $10 \mathrm{~g}$; 1 liter of distilled water). The inoculated flasks were placed on an enclosed, horizontal shaker (Takasaki Seisakusho Co., Japan) 
and agitated (about 90 cycles $/ \mathrm{min}$.) at $28^{\circ} \mathrm{C}$ for 48 hours in continuous darkness.

Electron Microscopy. Coverslip cultures of $G$. candidum (Fig. 1) were prepared for the scanning electron microscope (SEM) as described earlier ${ }^{18)}$. Isolated wall samples examined in the SEM (Fig. 7) were initially fixed in $2.5 \%$ glutaraldehyde buffered with $0.1 \mathrm{M}$ sodium cacodylate ( $\mathrm{pH} 7.1$ ) at $4^{\circ} \mathrm{C}$ for one hour. The wall material was then washed in buffer, dehydrated in an ethanol series, and finally transferred to absolute acetone. Droplets of the wall sample were air dried on the surface of clean coverslips which were then mounted on specimen stubs and coated in a Denton DV 502 evaporator equipped with a triode suptter coating device. Specimens were examined in an AMR model 1000 SEM using $30 \mathrm{kV}$ and photographed with Polaroid Type $55 \mathrm{P} / \mathrm{N}$ film.

Conidia examined by freeze-etching were grown on agar in Petri dish cultures and prepared according to the procedure outlined by Cole $\left.(1973)^{19}\right)$. Replicas were obtained using a Balzers BA 360 M Freeze-etch Device and examined in a Hitachi HU-11E transmission electron microscope.

Thin sections of G. candidum conidia were prepared by the procedure described in an earlier report ${ }^{8)}$.

Conidial Wall Isolation and Purification. Liquid cultures were slowly strained through eight layers of cheesecloth to remove mycelium from the cell suspension. The conidial filtrate was examined in the light microscope to check that essentially all hyphae has been removed. The conidial suspension was then centrifuged at $120 \mathrm{~g}$ for ten minutes. The pellet was washed and centrifuged at $120 \mathrm{~g}$ three times to remove residual growth media from the cells. The cells were fractured using acidcleaned, $0.45-0.50 \mathrm{~mm}$ glass beads in a Bronwill mechanical cell homogenizer (Braun Model MSK; Bronwill Sci. Inc., Rochester, New York). A ratio of $1 \mathrm{~g}$ wet weight of packed cells (after centrifugation at 120 for ten minutes) to $5 \mathrm{~g}$ glass beads was employed. The $75 \mathrm{ml}$ glass homogenization flask was cooled with liquid $\mathrm{CO}_{2}$ during the cell fraction procudere. The suspension of ruptured cells was subsequently centrifuged at $180 \mathrm{~g}$ for 15 minutes. The supernatant was discarded and the wall pellet was washed with distilled water and centrifuged at $180 \mathrm{~g}$ three times. The sample was then resusended in distilled water and subjected to mild sonication (five minutes, setting 4, Branson Sonifier, Branson
Sonic Power Co., Danbury, Conn.) to remove cytoplasmic debris attached to the wall surface. The suspension was subsequently centrifuged at $180 \mathrm{~g}$, the supernatant discarded and the pellet washed an additional three times. A sample of the wall material was then processed for SEM examination while the rest was lyophilized in preparation for chemical analyses.

Chemical Analyses. The procedures used in analysis of wall components of $C$. candidum were the same as those described by Cole et al. ${ }^{20)}$.

\section{OBSERVATIONS AND DISGUSSION}

When grown at $28^{\circ} \mathrm{C}$ on Czapek agar supplemented with $1 \%$ yeast extract, prolific conidial production occurs after four to five days. The same mode of conidiogenesis is demonstrated when the fungus is grown at $23^{\circ} \mathrm{C}$ on a thin layer of potato dextrose agar (Difco) which coats the surface of a glass coverslip ${ }^{18)}$. The cylindrical hypha in Fig. 1 has undergone septation and has partially disarticulated. In a time-lapse analysis of this process, Cole and Kendrick (1969) ${ }^{21)}$ have shown that a rapid succession of septation of the fertile hypha occurs shortly after the arrest of hyphal tip growth. It has been postulated that the latter event is associated with dispersion of a cluster of secretory vesicles at the hyphal apex which had been previously involved in maintaining the polarity of wall synthesis and intussusception at the apical dome of the vegetative filament $\left.{ }^{22} \sim 27\right)$. It seems that during hyphal elongation microvesicles which are components of the cluster of secretory vesicles fuse with the plasmalemma and thereby transport chitin synthetase to, or activate the zymogenic form of this enzyme necessary for wall fibrillogenesis at the hyphal tip ${ }^{28)}$. Just prior to the succession of septation which leads to conidium differentiation in $G$. candidum, however, vesicle fusion is apparently arrested at the hyphal tip. From the standpoint of current molecular models which explain membrane fusion as a $\mathrm{Ca}^{2+-i n d u c e d ~ p h a s e ~ c h a n g e ~}{ }^{29)}$, the programmed inhibition of membrane fusion and related morphogenetic events in G. candidum may be useful for studying the association between calcium ions and calcium binding proteins (e.g. calmodulin), and the process of fusion of secretory vesicles with the plasmalemma in fungal hyphae.

Septation of the determinate, fertile hypha is at first acropetal but is later random. In spite of this apparent haphazard sequence of crosswall forma- 
tion, each conidium shown in Fig. 1 contains a single nucleus ${ }^{30}$ ). Just prior to septation, nuclei are more or less regularly spaced within the hypha. Crosswalls subsequently form so that large hyphal compartments are delimited, each containing two nuclei. These compartments then divide, resulting in differentiation of conidia each containing a single nucleus. Such observations suggest that both temporal and spatial associations may exist between initiation of septation on the one hand, and positioning of nuclei and nuclear division on the other. Recent ultrastructural studies of septation in hyphae utilizing improved techniques of cryofixation $^{31)}$ and chemical fixation have revealed a ring or belt of microfilaments attached to the plasmalemma prior to the first signs of crosswall formation ${ }^{32)}$. This latter author has pointed out that microfilaments can attach to membranes of other organelles in fungal hyphae, including microvesicles, which "may partially fulfill the demand for sequestration of factors needed for septum formation. It is possible..." that the microfilamentous belt works mainly as a mechanical device for entrapment of vesicles... bearing chitin synthetase and... other vesicles with proteases for activation of the zymogen". Although cytochalasin B has no apparent effect on these microfilaments ${ }^{32)}$, cytochalashin $A$ has been shown to influence intracellular organization associated with wall deposition in hyphae (i.e. arrangement and fusion of microvesicles with the cell membrane) ${ }^{33,34)}$. Employing cytochalasin A for studies of septation in G. candidum during conidium formation may prove useful for determining the interrelationships of microfilaments, microvesicles, wall deposition and wall growth in fungal hyphae ${ }^{26)}$.

Thin sections have revealed that the mature septa of vegetative and fertile hyphae of G. candidum are structurally distinct ${ }^{25}$ ). The crosswalls of vegetative hyphae are uniperforate and demonstrate morphological features which are typical of the anamorphs of ascomycetous fungi ${ }^{35)}$. As long as the septal pore is open, adjacent cells are cytoplasmically connected and the pore is usually large enough to permit passage of nuclei, mitochondria and other organelles between cells. On the other hand, the septa which delimit conidia are multiperforate, and each micropore ${ }^{36,37)}$ or plasmadesmal canal ${ }^{38}$ ) is approximately $0.02 \mu \mathrm{m}$ in diameter. In Fig. 2, a tangential section of a conidial septum reveals several micropores $(M)$. When the conidium is mature, the pores of the multiperforate septum are occluded by electron dense material so that adjacent cells are cytoplasmically separated. The cytological events and details of wall differentiation associated with multiperforate septum formation are underscribed.

Ultrastructural examinations of condiogenesis in $G$. candidum have shown that the entire wall of the fertile hypha is incorporated into that of the conidia. Thickening of the inner wall layer and differentiation of crosswalls appear to be the only events involving new wall synthesis which occur during conidium formation. This is reflected in certain similarities in chemical composition between the hyphal and conidial walls which will be discussed later. During secession of adjacent conidia, the crosswalls split centripetally, a process which is referred to as schizolysis in septate fungiigi ${ }^{25,27,39,40}$ ). As a result of disarticulation of the fertile hypha, the outer wall layer ruptures at the septa but persists as a frill at the ends of the conidia (Fig. 3). The significance of these data is that all wall layers of the fertile hypha become integrated into the conidial wall. This mode of conidiogenesis is called holoarthric development ${ }^{25)}$. However, another method of conidium formation has been reported for G. candidum and G. loubieri in which chains of conidia are formed endogeneously in the fertile hypha, disarticulate and are then released by breakdown of the outer hyphal wall ${ }^{41,42}$. This kind of conidiogenesis is referred to as enteroarthric development and has been considered to characterize such septate fungi as Sporendonema, Coremiella and Coccidio$i_{\text {des }}^{8,25)}$. A diagrammatic interpretation of wall differentiation during holoarthric and enteroarthric conidium formation is presented in Fig. $4^{25)}$. Most strains of $G$. candidum demonstrate holoarthric conidium formation. However, when Saez ${ }^{41)}$ grew his isolate on Sabourand's glucose ( $2 \%$ ) agar at $25-30^{\circ} \mathrm{C}$ for two to three weeks, abundant enteroarttthric conidia were formed especially near the outer perimeter of the colony. Using both holoarthric and enteroarthric strains of G. candidum, a comparison of wall chemistry and the ultrastructural events associated with wall differentiation during these two developmental processes may be performed. Of special interest is the suggested presence of digestive enzymes associated with wall lysis during both enteroarthric and 

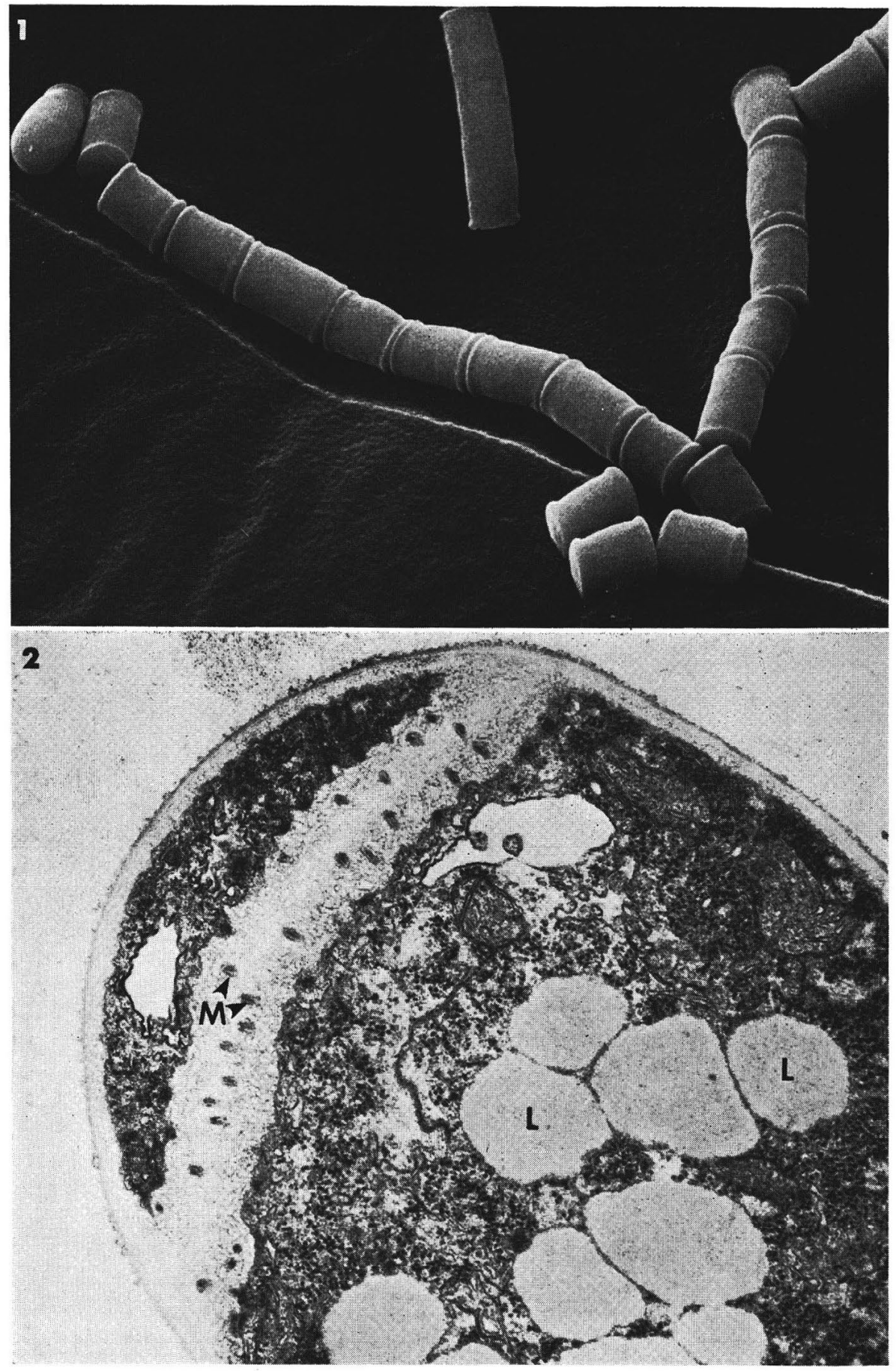

Fig. 1. Coverslip culture of Geotrichum candidum showing conidia which have formed by disarticulation of a fertile hypha. $\times 2,750$. (from Cole and Samson, 1979).

Fig. 2. Tangential section of conidial septum showing multiperforate nature of cross wall. L, lipid droplets; M, micropores; Mt, mitochondria. ×36,000. 


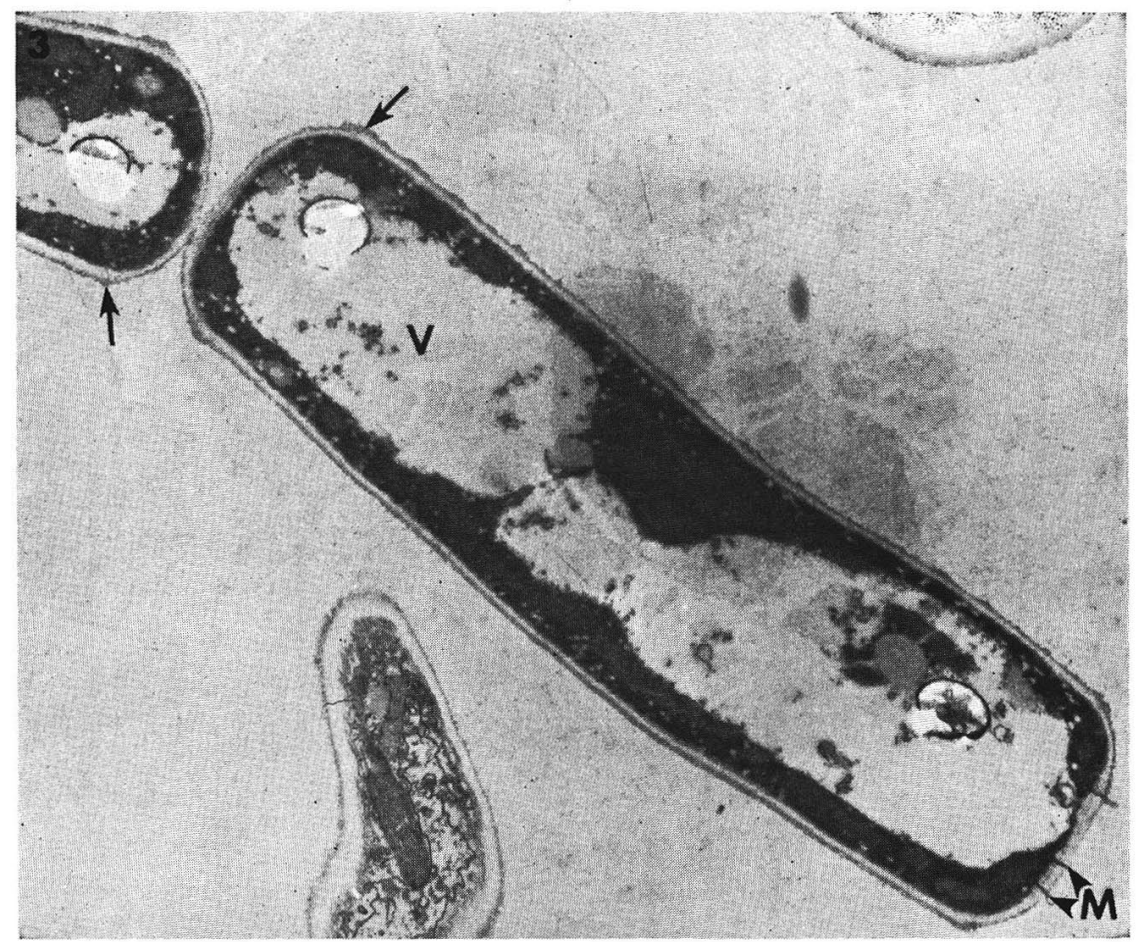

Fig. 3. Adjacent conidia showing ruptured outermost wall layer which remains as a frill of wall material (arrows) at the ends of the cells. M, micropores; V, vacuole. $\times 12,000$.

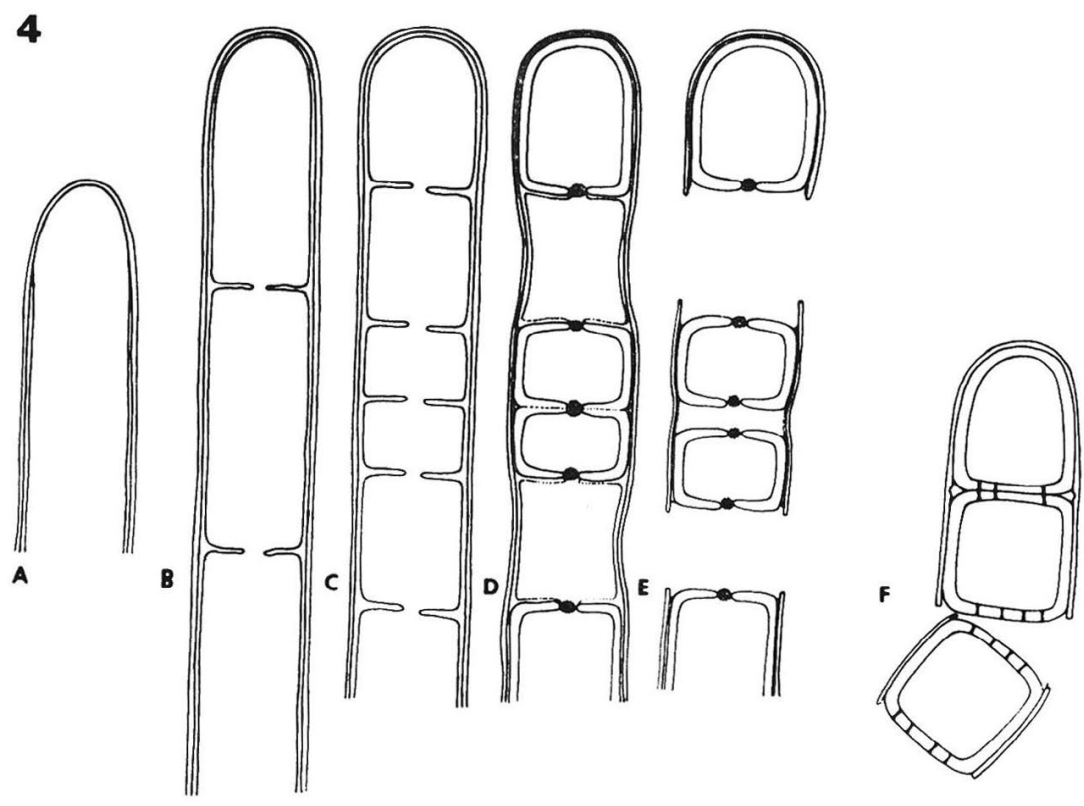

Fig. 4. Diagrammatic interpretation of holoarthric (A, B, F) and enteroarthric $(A-E)$ conidium formation. (after Cole and Samson, 1979). 
holoarthric conidium formation ${ }^{10,25)}$ but their apparent differences in sites of action and/or substrates are unknown.

In a pioneering study of exogenous and endogenous factors controlling conidiogenesis in G. candidum, Park and Robinson') demonstrated that vegetative growth is maintained under conditions of high nutrient levels of carbon and nitrogen sources but may be induced as these nutrients are depleted. The authors suggested that a certain endogenous condition is necessary for maintenance of "apical integrity" and polarized growth of vegetative hyphae. This endogenous condition is sustained by the availability of exogenous carbon and nitrogen sources. After several days of starvation, it was proposed that the endogenous condition may break down in some, but not all, of the hyphae, which then revert to the resting phase with production of arthrospores (holoarthric conidia). Another suggested possibility was that depletion of exogenous nutrients essential for vegetative growth leads to accumulation of a diffusible metabolite which induces sporulation to occur. The effects of differing nutrient levels of carbon and nitrogen sources on growth and differentiation of $G$. candidum have since been investigated using chemostat and batch culture techniques ${ }^{11,12,15 \sim 17) .}$ Robinson and Smith (1979) ${ }^{15}$ ) compared hyphal growth of $G$. candidum on solid agar with that in chemostat culture. At high initial glucose concentrations in solid media, the marginal hyphae of the colony establish a steep concentration gradient in glucose from the "apices of the leader hyphe to the more proximal non-apical cells". The gradient steepens as apical branching occurs. Metabolites released by non-apical cells may participate in the inhibition of extension growth and stimulation of septation and conidium development. When grown either in steady-state glucose-limited chemostat culture or on solid media with low initial glucose concentrations, the cell dimensions and hyphal extension rates of $G$. candidum are similar ${ }^{16)}$. it was suggested that similar nutrient concentration gradients exist under these two growth conditions. In both cases, an increase in temperature results in a decrease in hyphal diameter, cell length and cell volume. Aeration also plays a role in hyphal differentiation. Cultures grown on solid media reveal differentiated surface and submerged, marginal hyphae. While the former are broad, septate and branched, the latter are unbranched, have longer cells and are narrow. Such differences are probably the result of competition for oxygen ${ }^{43)}$.

Park and Robinson ${ }^{9)}$ proposed that the supply of carbon and nitrogen have separate effects on conidium formation: Time to sporulation is reduced when glucose only is present, whereas a nitrogen source alone increases the time to sporulation. When grown in both culture using simple, synthetic media with an initial glucose concentration of $0.5 \%$, two different exponential growth phases are demonstrated ${ }^{11,12}$. The first phase involves an increase in mycelial growth while the second, after only $15 \%$ of the original glucose and $30 \%$ of the ammonium have been consumed, involves conidium formation. At low initial glucose concentration in the growth medium (e.g. $0.1 \%$ ), one exponential growth phase occurs. The fungus uses up all the exogenous glucose and conidia are then formed in stationary phase. The holoarthric conidia produced under these different growth conditions are morphologically and biochemically distinct (Table 4$)^{17}$ ). At the higher initial glucose concentration $(0.5 \%)$, short ellipsoidal conidia were predominant, while in media with a lower initial glucose concentration $(0.1 \%)$, long, cylindrical conidia were formed ${ }^{11,17)}$.

Thin sections of $G$. candidum conidia reveal a fine, outer electron translucent wall layer which seems to be discontinuous (OW, Fig. 5). Wall material has also apparently sloughed off the surface of the cell (arrows in Fig. 5). Freeze-fractures of conidial walls show fascicles of short fibrils called 'rodlets' (Fig. 6) which have been observed on the surface of conidia produced by many imperfect fungi $19,20,25)$. The apparent discontinuity of the rodlet layer in Fig. 6 corresponds with the discontinuous outer wall (OW) shown in Fig. 5 . The chemistry of rodlets of conidial fungi has been examined by several authors and identified as a crystallized protein ${ }^{44} 46$ ) or a lipoprotein complex ${ }^{47)}$. When conidia of Aspergillus niger were treated with non-ionic detergents (e.g. Nonidet P40), wall components were extracted without any significant structural changes to the rodlet layer 47 ). This suggests that the latter may function as a sieve through which macromolecular components of the inner wall layer may be leaked. Isolated rodlets are hydrophobic which suggests that they facilitate dis. semination of propagules in moist or aquatic environments ${ }^{48}$ ). In fact rodlets have been observed 


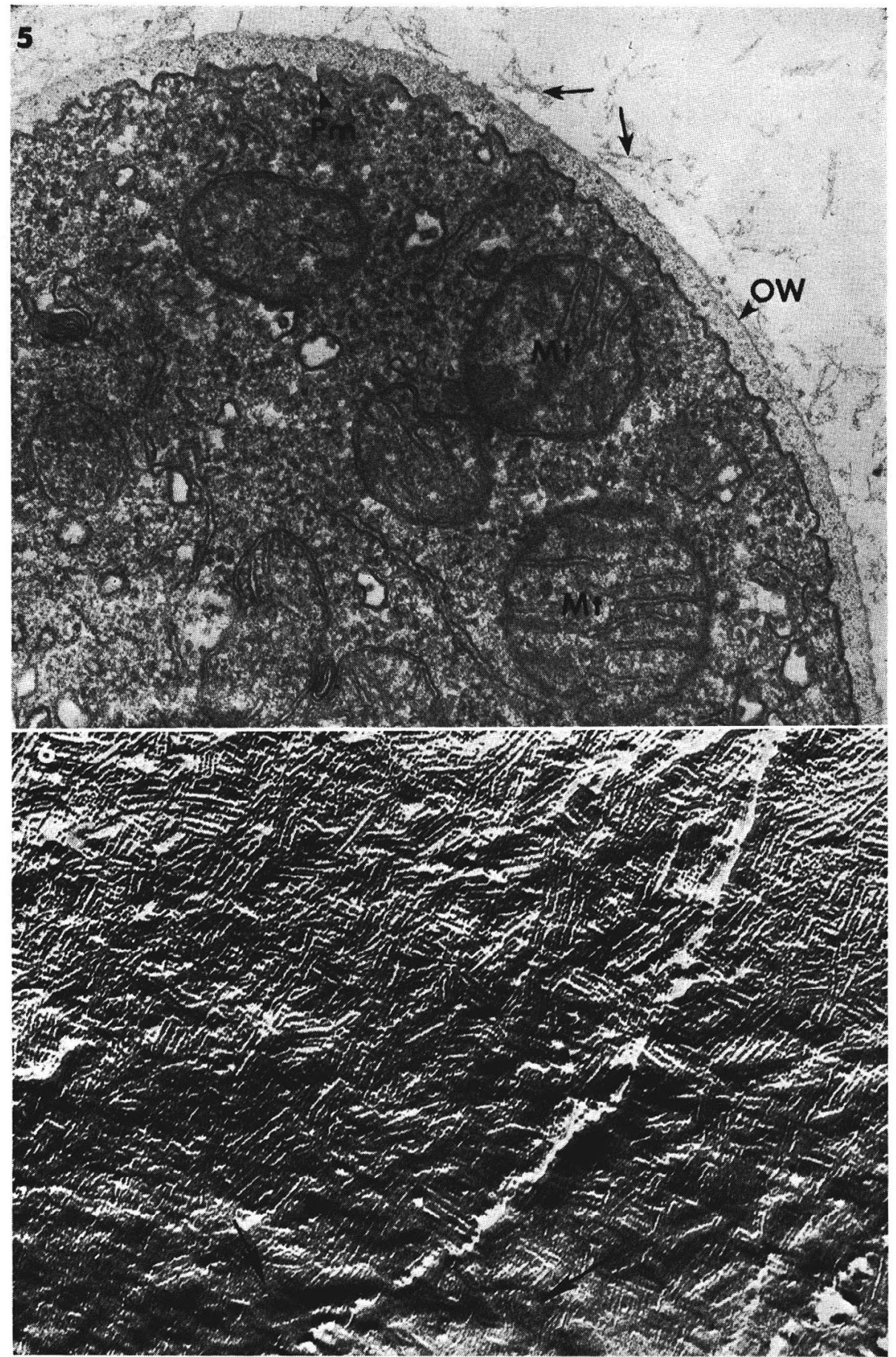

Fig. 5. Thin section of the conidial wall of $G$. candidum. The outer wall layer $(O W)$ is discontinuous and some wall material (arrows) has apparently sloughed off the cell. Mt, mitochondria; Pm, plasmalemma. $\times 61,200$.

Fig. 6. Freeze-fracture of the conidial wall of $G$. condidum showing fascicles of 'rodlets'. Arrows indicate regions of apparent discontinuity of the rodlet layer. $\times 111,000$. (after Cole, 1973). 


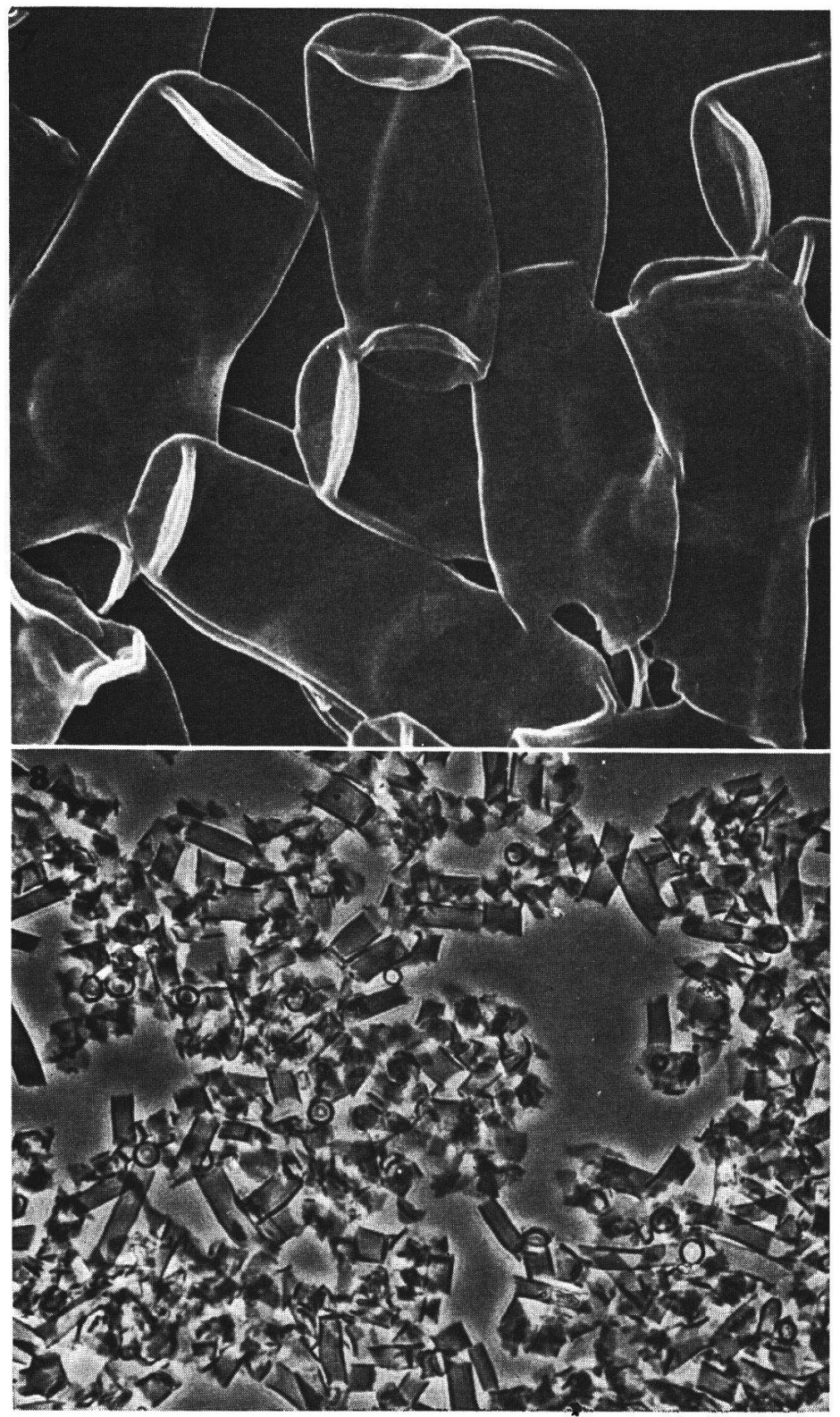

Fig. 7. Isolated conidial walls of $G$. candidum examined with the SEM. $\times 3,240$.

Fig. 8. Isolated conidial walls of $G$. candidum obtained by cell homogenization showing high degree of purity. $\times 800$.

only on the wall surface of aerially grown cells and in the Fungi Imperfecti, only on conidia. Wessels et al. ${ }^{49}$, however, has reported rodlet fascicles on the hyphal wall of the Basidiomycete, Schizophyl- lum commune and identified rodlet composition as primarily S-glucan. In $G$. candidum, rodlets have not been found on the hyphal wall surface. Only aerial chains of holoarthric conidia produced by 
mycelia grown on solid agar media have been shown to have a rodlet layer which is exposed by freeze-fracturing. Direct replication of these cells does not expose the rodlet fascicles and not all surface fractures of aerial conidia reveal the rodlet layer. We suggest that the outermost wall material which is bound to and may have been released through the rodlet layer from inner wall layers (Fig. 5). This outermost layer affects the plane of fracture during freeze-fracturing so that only rare surface fractures occur over or between the rodlet fascicles. An outermost amorphous layer has been demonstrated on the conidial walls of Trichophyton mentagrophytes ${ }^{45)}$, Cladosporium macrocarpum and Aspergillus niger ${ }^{20}$ ). Our knowledge of rodlet ultrastructure, chemical composition and function is still rather scanty. The apparent morphological similarity of rodlet fascicles on the surface of aerial propagules produced by members of all groups of septate fungi as well as filamentous bacteria ${ }^{50}$ ), suggests a common function. The degree of similarity in chemical composition of rodlets requires additional comparative investigations.

Mechanisms of conidiogenesis and the chemical composition of conidial and fertile hyphal walls are considered to be interrelated. On the basis of this premise, a comparison of the wall chemistry of various stages of fungal cell development should reveal certain trends which reflect relationships between alterations in wall composition and morphogenesis ${ }^{51)}$. Since G. candidum demonstrates a simple process of conidium ontogeny, this fungus is a good model for correlating such data. In this study, conidia were harvested from stationary phase cultures using media with an initially high carbon source nutrient level ( $30 \mathrm{~g}$ sucrose/liter). Extreme care was taken to isolate conidia only from the culture media. Our procedure of homogenization resulted in $\mathbf{9 5 \%}$ cell rupture (Fig. $7,8)$. Care was also taken to throughly wash the conidia before and after homogenization to remove media and cytoplasmic debris, respectively, from the wall surface. A summary of the chemical composition of the conidial wall is presented in Table 1. The values represent averages of data from four different wall preparations. No significant variations in data for the individual analyses or total recovery were found. The total carbohydrate content was high while total peptide and lipid contents were low. The percentage of hexosamine in the conidial wall was also relatively high. Mannose was the predominant monosaccharide while galactose and glucose occurred in approximately equal proportions. Threonine and aspartic acid were the major amino acids (Table 2 ). Comparable percentages were determined for serine, valine and alanine on the one hand, and glutamic acid, proline and glycine on the other. The fatty acid composition of the readily extractable and bound lipids obtained from the conidial walls were examined by gas-liquid chromatography (Table 3). Oleic, linoleic and iso-palmitic acid occurred in the largest amounts. The concentration of palmitoleic acid was about two times greater in the bound than the readily extractable lipid form.

In Table 4, a comparison is presented between the composition of hyphal and holoarthric conidial walls produced by $T$. mentagrophytes and $G$. candidum. In each case, the ratio of total neutral carbohydrate/protein is high. A distinct similarity is also evident between the total hexosamine content of hyphal and conidial walls. Cole and Samson ${ }^{26)}$ have suggested that such similarities in the composition of hyphal and holoarthric conidial walls is a reflection of the mode of conidiogenesis: holoarthric conidia are formed by simple fragmentation and involve little new wall synthesis. Their chemical composition, therefore, would be expected comparable to that of the hyphae from

Table 1. Summary of chemical composition of the conidial wall of Geotrichum candidum

\begin{tabular}{lc}
\hline \multicolumn{1}{c}{ Component } & $\%$ \\
\hline Carbohydrate & 69.7 \\
Mannose & $(54.7)^{a}$ \\
Galactose & $(21.6)$ \\
Glucose & $(23.7)$ \\
Hexosamine & 12.2 \\
Peptide & 8.3 \\
Lipid & \\
Readily extractable & \\
Lipid & 0.5 \\
Bound Lipid & 0.8 \\
RNA & 1.7 \\
DNA & - \\
\hline
\end{tabular}

a Monosaccharide content expressed as percentage of total carbohydrate. 
which they formed. In contrast, the authors have pointed out that the chemical composition of

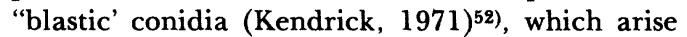
by de novo growth and involve a considerable

Table 2. Amino acid composition of the conidial wall of Geotrichum candidum

\begin{tabular}{lc}
\hline Amino Acid & Mol \% ${ }^{a}$ \\
\hline Asparatic Acid & 15.0 \\
Threonine & 17.6 \\
Serine & 10.2 \\
Glutamic Acid & 7.1 \\
Proline & 7.6 \\
Glycine & 7.4 \\
Alanine & 8.7 \\
Cystine & 0.5 \\
Valine & 9.0 \\
Methionine & $\mathrm{n} . \mathrm{d}^{b}$ \\
Isoleucine & 5.2 \\
Leucine & 3.0 \\
Tyrosine & 1.3 \\
Phenylalanine & 1.4 \\
Histidine & 1.2 \\
Lysine & 3.9 \\
Arginine & 0.9 \\
\hline$a$ Based on maximum yield values after acid \\
hydrolysis except tryptophan. \\
$b$ Not detected.
\end{tabular}

amount of new wall synthesis, shows marked differences to the composition of corresponding hyphal walls. However, some differences do exist in the peptide, lipid and monosaccharide content between hyphal and holoarthric conidial walls which may be significant in morphogenesis. For example, Hashimoto et al. ${ }^{53)}$ have reported marked decreases in peptide and lipid content of conidial walls compared to hyphal walls of $T$. mentagro-

Table 3. Fatty acid composition of the readily extractable and bound lipid components of the conidial wall of Geotrichum candidum

\begin{tabular}{lrrr}
\hline \multicolumn{1}{c}{ Fatty acid } & & $\begin{array}{c}\text { Readily } \\
\text { extractable } \\
\text { lipid }\end{array}$ & Bound lipid \\
& & B \\
Lauric & $\mathrm{C} 12: 0$ & 0.6 & 0.8 \\
Myristic & $\mathrm{C} 14: 0$ & 3.5 & 5.0 \\
Pentadecylic & $\mathrm{C} 15: 0$ & 2.1 & 3.1 \\
isopPalmitic & iso-C16:0 & 18.7 & 26.1 \\
Palmitoleic & $\mathrm{C} 16: 1$ & 6.1 & 13.9 \\
Stearic & $\mathrm{C} 18: 0$ & 5.0 & 6.4 \\
Oleic & $\mathrm{C} 18: 1$ & 27.7 & 20.4 \\
Linoleic & $\mathrm{C} 18: 2$ & 27.3 & 13.0 \\
\hline
\end{tabular}

a Values expressed as percentages of the total lipid in each fraction.

Table 4. Comparison of cell wall composition of vegetative hyphae and holoarthric conidia

\begin{tabular}{ccccc}
\hline Component & $\begin{array}{c}\text { Trichophyton } \\
\text { mentagrophytes } \\
\text { (hyphae) } \\
\%\end{array}$ & $\begin{array}{c}\text { Trichophyton } \\
\text { mentagrophytes } \\
\text { (holoarthric } \\
\text { conidia) } \%\end{array}$ & $\begin{array}{c}\text { Geotrichumc } \\
\text { candidum } \\
\text { (hyphae) } \\
\%\end{array}$ & $\begin{array}{c}\text { Geotrichum } \\
\text { candidum } \\
\text { (holoarthric } \\
\text { conidia) \% }\end{array}$ \\
\hline Total neutral & & & & \\
carbohydrates & 47.9 & 53.0 & $60.3[56.8]$ & $57.3[50.6 / 51.2]$ \\
Mannose & $(11.7)^{e}$ & + & $(5.0)$ & $(7.0)$ \\
Galactose & $\operatorname{tr} f$ & + & $(4.0)$ & $(4.0)$ \\
Glucose & $(36.2)$ & + & $(86.0)$ & $(83.0)$ \\
Hexosamine & 30.4 & $30.0 \mathrm{9}$ & 9.7 & 8.0 \\
Peptide & 7.8 & 3.0 & $8.8[5.0]$ & $11.9[6.7 / 7.5]$ \\
Lipid & 6.6 & 1.0 & $5.3[1.0]$ & $5.8[1.0 / 1.0]$ \\
\hline
\end{tabular}

a Data from Noguchi et al., 1971.

$b$ Data from Hashimoto et al., 1979.

c Two sets of data for hyphal wall composition of G. candidum from Ebina et al., 1978 (left column) and Kier et al., 1980 (data enclosed by square brackets).

d Two sets of data reported for holoarthric conidia from Ebina et al., 1978 (left column) and Kier et al., 1980 (data enclosed by square brackets indicate composition of two kinds of holoarthric conidia produced under different growth conditionals; cylindrical conidia/ellipsoidal conidia).

$e$ Monosaccharide content expressed as percentage of total carbohydrate.

$f$ Trace.

$g$ Expressed as chitin in original source. 
phytes (Table 4). Similarly, our determination of the total lipid content of conidial walls of $G$. candidum (1.3\%, Table 1) contrasts with the lipid composition of hyphal walls of this same fungus

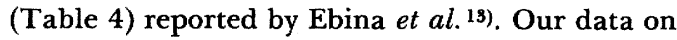
monosaccharide composition of $G$. candidum conidial walls differs sharply from that reported by other authors ${ }^{13,17}$ ). One possible explanation for these differences could be the variation in original carbohydrate content of the media. While our initial sucrose concentration was $3 \%$, the original concentration of glucose in the media used by Ebina et al. ${ }^{13)}$ was $1 \%$, and the initial glucose concentrations used by Kier et al. ${ }^{17}$ ) for growth of cylindrical and ellipsoidal conidia were $0.1 \%$ and $0.5 \%$, respectively. The importance of carbon nutrient levels of the growth media to morphogenesis in G. candidum has long been recognized ${ }^{9}$. Selective incorporation of monosaccharides into existing and newly synthesized walls may give rise to differences in structure and physical properties of cell walls which, in turn, may lead to different cellular morphologies ${ }^{54)}$.

\section{ACKNOWLEDGEMENTS}

This research was supported by a National Science Foundation Cooperative Fellowship (INT77-14420) awarded to G.T.C. and the Japan Society for Promotion of Science. A National Science Foundation grant (DEB76-01836) and National Institute of Health Grant (NIH AI 15583) awarded to G.T.C. also provided support for this research.

\section{REFERENCES}

1) Barron, G.L.: The genera of hyphomycetes from soil. Williams and Wilkins Co., Baltimore, 1986.

2) Pitt, J.I.: Food spoilage and biodeterioration. In biology of conidial fungi. G.T. Cole and B. Kendrick (Eds.), Vol. 2, Academic Press, New York, 1981.

3) Emmons, C.W., Binford, C.H., Utz, J.P. and Kwon-Chung, K.J.: In Medical mycology. 3rd. ed. Lea and Febiger, Philadelphia, 1977.

4) Ainsworth, G.C. and Austwick, P.K.C.: Fungal diseases of animals. Commonwealth Agriculture Bureau, Slough, England, 1973.

5) Sinclair, J.B. and El-Tobshy, Z.M.: Pathogenicity of 'plant and animal isolates of Geotrichum candidum in the turtle. Mycologia, 61:473-480, 1969.

6) Spanoghe, L., Devos, A. and Viaene, N.: Cutaneous geotrichosis in the red flamingo (Phoenicopterus ruber). Sabouraudia, 14: 37-42, 1976.

7) Ruiz, J.Ma., Arteaga, E., Martinez, J., Rubio, E.M. and Torres, J.Ma.: Cutaneous and renal Geotrichosis in a giant tortoise (Geochelone elephantopus). Sabouraudia, 18: $51-59,1980$.

8) Cole, G.T.: The thallic mode of conidiogenesis in the fungi imperfecti. Can. J. Bot., 53: 2983-3001, $1975 a$.

9) Park, D. and Robinson, P.M.: Sporulation in Geotrichum candidum. Trans. Br. Mycol. Soc., 52: 213-222, 1969.

10) Trinci, A.P.J. and Collinge, A.J.: Spore formation in nitrogen and carbon starved cultures of Geotrichum candidum and Mucor racemosus. Trans. Br. Mycol. Soc., 62: 351-358, 1974.

11) Kier, I., Allermann, K., Floto, F. and Sortkjaer, O.: Changes of exponential growth rates in relation to differentiation of Geotrichum candidum in submerged culture. Physiol. Plant., 38: 6-12, 1976.

12) Allermann, K., Floto, F., Olsen, J., Sortkjaer, O. and Kier, I.: Sporulation and the macromolecular composition of the mycelium and arthrospores of Geotrichum candidum. Physiol Plant., 42: $355-$ $358,1978$.

13) Ebina, K., Takashita, S., Kamaguchi, A., Yokota, K. and Sakaguchi, O.: Comparison of cell body and cell wall compositions between the yeast-like and mycelial phases of Geotrichum candidum. Jap. J. Bacteriol., 33: 527-538, 1978.

14) Cotter, D.A. and Martel, A.J.: Acid phosphatase activity and polyol levels during the life cycle of Geotrichum sp. Microbios Lett., 8: 85-93, 1979.

15) Robinson, P.M. and Smith, J.M.: Development of cells and hyphae of Geotrichum candidum in chemostat and batch culture. Trans. Br. Mycol. Soc., 72: 39-47, 1979.

16) Smith, J.M. and Robinson, P.M.: Development of sonatic hyphae of Geotrichum candidum. Trans. Br. Mycol. Soc., 74: 159-165, 1980.

17) Kier, I., Floto, F., Olsen, J. and Allermann, K.: Macromolecular composition of the wall and protoplasm of mycelia and arthrospores of Geotrichum candidum. Trans. Br. Mycol. Soc., in press.

18) Cole, G.T.: A preparatory technique for examination of imperfect fungi by scanning electron microscopy. Cytobios., 12: 115-121, 1975b.

19) Cole, G.T.: A correlation between rodlet orientation and condiogenesis in hyphomycetes. Can. J. Bot., 51: 2413-2422, 1973.

20) Cole, G.T., Sekiya, T., Kasai, R., Yokoyama, T. and Nozawa, Y.: Surface ultrastructure and composition of the cell walls of conidial fungi. Exp. Mycol., 3: 132-156, 1979.

21) Cole, G.T. and Kendrick, W.B.: Conidium ontog ency in hyphomycetes. The arthrospores of Oidiodendron and Geotrichum and the endoarthrospores 
of Pporendonema. Can J. Bot., 47: 1773-1780, 1969.

22) Girbardt, M.: Lebendbeobachdungen an Polystictus versicolor (L). Flora., 142: 540-563, 1955.

23) Girbardt, M.: Der Spitzenkörper von Polystictus ver sicolor (L). Planta, Berlin, 50: 47-59, 1957.

24) Grove, S.M. and Backer, L.E.: Protoplasmic organization of hyphal tips among fungi: vesicles and Spitzenkörper. J. Bacteriol., 104: 989-1009, 1970.

25) Cole, G.T. and Samson, R.A.: Patterns of development in conidial fungi. Pitman Pub., London, 1979.

26) Cole, G.T. and Samson, R.A.: Conidium and sporangiospore formation in pathogenic microfungi. In Pathogenic fungi: Their biology, pathogenicity, and selection. Vol. I.D. Howard (Ed.) Marcel Dekker, New York. (in press), 1981.

27) Cole, G.T.: Conisiogenesis and conidiomatal ontogeny. In Biology of conidial fungi, Vol. 2. G.T. Cole and B. Kendrick, (Eds.), p. 270-237, Academic Press, New York, 1981.

28) Bartnicki-Garcia, S., Ruiz-Herrera, J. and Bracker, C.E.: Chitosomes and chitin synthesis. In Fungal walls and hyphal growth, J.H. Burnett and A.P.J. Trinci (Eds.), p. 149-168, Cambride University Press, Cambridge, 1979.

29) Papahadjopoulos, D., Poste, G. and Vail, W.J.: Studies on membrane fusion with natural and model membranes. In Methods in membrane biology. E.D. Korn (Ed.), p. 1-121, Plenum Press, New York, 1979.

30) Kendrick, W.B. and Chang, M.G.: Karyology of conidiogenesis in some hyphomycetes. In Taxonomy of fungi imperfecti, W.B. Kendrick (Ed.), p. 279291, University of Toronto Press, Toronto, 1971.

31) Hoch, H.C. and Howard, R.J.: Ultrastructure of freeze-substituted hyphae of the basidiomycete Laetisaria arvalis. Protoplasma, 103: 281-297, 1980.

32) Girbardt, M.: A microfilamentous septal belt (FSB) during induction of cytokinesis in Trametes versicolor (L. ex Fr.) Exp. Mycol., 3: 215-228, 1979.

33) Thomas, D.: Cytochalasin effects in plants and eukaryotic microbial systems. In Cytochalasin - biomedical and cell biological aspects. S.W. Tanenbaum (Ed.), Elsevier/North Holland Biomedical Press, Amsterdam, 1978.

34) Allen, E.D., Aiuto, R. and Sussman, A.S.: Effects of cytochalasins on Neurospora crassa. In Growth and ultrastructure. Protoplasma, 102: 63-75, 1980.

35) Moore, R.T. and McAlear, J.H.: Fine structure of mycota. 7. Obsevations on septa of Ascomycetes and Basidiomycetes. Am. J. Botany, 49: 86-94, 1962.

36) Wilsenach, R.A. and Kessel, M.: The role of lomasomes in wall formation in Penicillium vermicu. latum. J. Gen. Microbiol., 40: 401 - 404, 1965.

37) Bracker, C.E.: Ultrastructure of fungi. Ann. Rev.
Phytopath., 5: 343-374, 1976.

38) Hashimoto, T., Morgan, J. and Conti, S.F.: Morphogenesis and ultrastructure of Geotrichum candidum septa. J. Bacteriol., 116: 447-455, 1973.

39) Hughes, S.J.: Percurrent proliferations in fungi, algae, and mosses. Can. J. Bot., 49: 215-231, $1971 \mathrm{a}$.

40) Hughes, S.J.: On conidia of fungi and geminae of algae, bryophytes, and pteridophytes. Can. J. Bot. 49: 1319-1339, 1971b.

41) Säez, H.: Formation d'endospores chez Geotrichum candidum. Annales de Parasitologie (paris), 44: 197-204, 1969.

42) Säez, H.: Geotrichum loubieri Morenz 1964, un champignon arthrospore, formant egalement des endospores. Bull. Mensuel de la Soc. Linnéenne de Lyon, No. 9, p. 283-288, 1970.

43) Robinson, P.M. and Griffith, P.J.: Effect of restricted aeration on chemotropism, morphogenesis and polarity of lateral branch induction in Geotrichum candidum link ex pers. Trans. Br. Mycol. Soc., 68: $311-314,1977$.

44) Hashimoto, T., Wu-Yuan, C.D. and Blumenthal, H.J.: Isolation and characterization of the rodlet layer of Trichophyton mentagrophytes microconidial wall. J. Bacteriol., 127: 1543-1549, 1976.

45) Wu-Yuan, C.D. and Hashimoto, T.: Architecture and chemistry of microconidial walls of Trichophyton mentagrophytes. J. Bacteriol., 129: 1584-1592, 1977.

46) Beever, R.E., Redgwell, R.J. and Dempsey, G.P.: Purification and chemical characterization of the rodlet layer of Neurospora crassa conidia. J. Bacteriol., 140: 1063-1070, 1979.

47) Cole, G.T. and Pope, L.M.: Surface wall components of Aspergillus niger conidia. In The fungal spore: Morphogenetic controls. H. Hohl and G. Turian (Eds.), Academic Press, New York. (in press), 1981.

48) Beever, R.E. and Dempsy, G.P.: Function of rodlets on the surface of fungal spores. Nature (London), 272: $608-610,1978$.

49) Wessels, J.G.H., Kreger, D.R., Marchant, R. Regensburg, B.A. and DeVries, O.M.H.: Chemical and morphological characterization of the hyphal wall surface of the basidiomycete Schizophyllum commune. Biochim. Biophys. Acta, 273: 346-358, 1972.

50) Smucker, R.A. and Pfister, R.M.: Characteristics of Streptomyces coelicolor $\operatorname{Ad}(2)$ aerial spore rodlet mosaic. Can. J. Microbiol., 24: 397-408, 1978.

51) Cole, G.T., Sekiya, T., Kasai, R. and Nozawa, Y.: Morphogenesis and wall chemistry of the yeast, "intermediate", and hyphal phases of the dimorphic fungus, Mycotypha poitrasii. Can. J. Microbiol., 26: $36-49,1980$. 
52) Kendrick, W.B. (Ed.): Taxonomy of fungi imperfecti. Univ. of Toronto Press, Toronto, 1971.

53) Hashimoto, T., Pollack J.H. and Blumenthal, H.J.: Ultrastructure and chemical composition of Trichophyton mentagrophytes arthrospore walls and septa. Ann. Meeting of the ASM. Miami, Fla. Abstract, p.
$92,1979$.

54) Dow, J.M. and Rubery, P.H.: Chemical fractionation of the cell walls of mycelial and yeast-like forms of Mucor rouxii: a comparative study of the polysaccharide and glycoprotein in Geotrichum candidum. J. Gen. Microbiol., 99: 29-41, 1977. 